\title{
Correction to: Detection and assessment of the phytotoxicity of residual organic pollutants in sediment contaminated with pulp and paper mill effluent
}

\author{
Sangeeta Yadav $\cdot$ Ram Chandra
}

Published online: 21 May 2021

(C) Springer Nature Switzerland AG 2021

Correction to: Environ Monit Assess (2018) 190:58 https://doi.org/10.1007/s10661-018-6947-1

The original version of this article unfortunately contained a mistake.

The Fig. 6 was published erroneously.

The corrected Fig. 6 is shown in the next page.

The original article can be found online at https://doi.org/ 10.1007/s10661-018-6947-1.

S. Yadav $\cdot$ R. Chandra $(\bowtie)$

Department of Environmental Microbiology, School for Environmental Sciences, Babasaheb Bhimrao Ambedkar University (A Central University), Vidya Vihar, Raebareli Road, Lucknow, Uttar Pradesh 226025, India e-mail: rc_microitrc@yahoo.co.in; prof.chandrabbau@ gmail.com

S. Yadav

e-mail: sangeeta_biotech12@rediffmail.com 

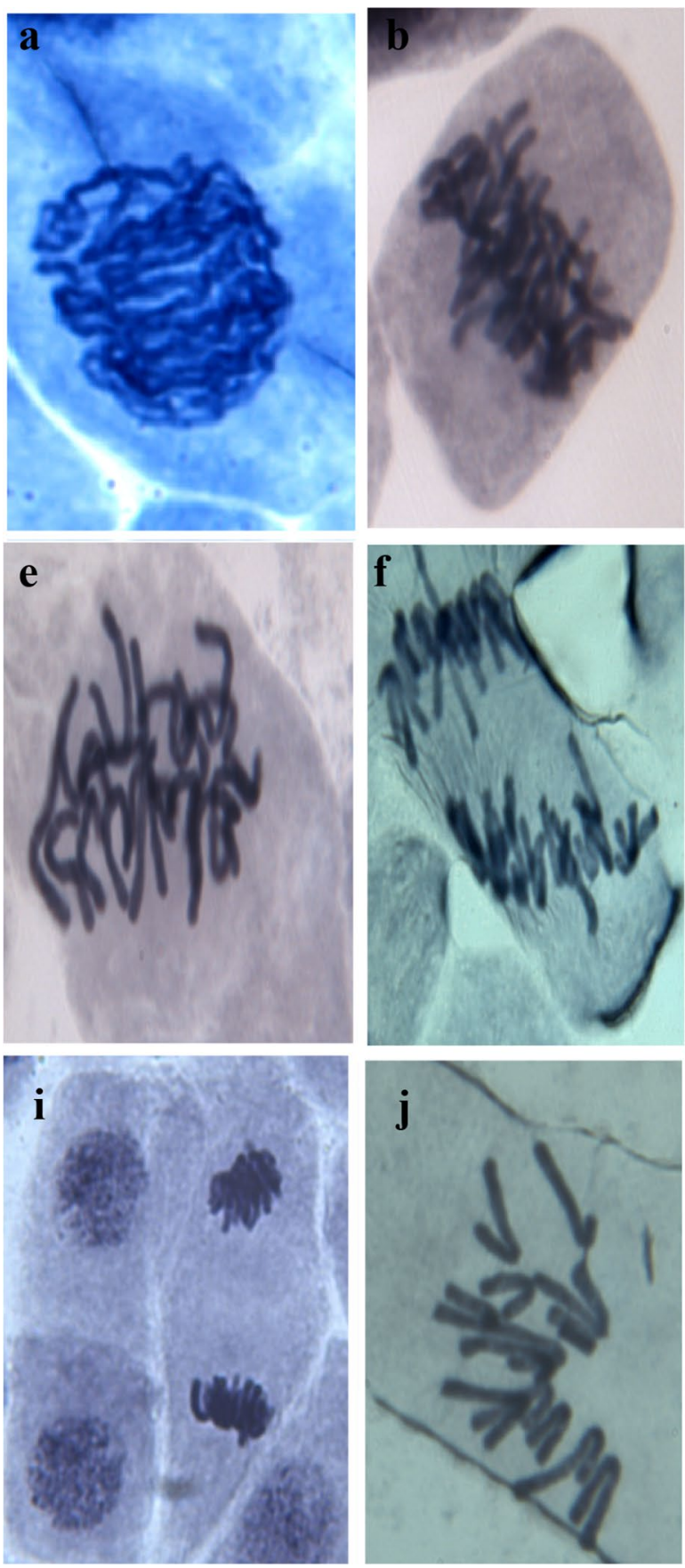

Fig. 6 Different chromosomal aberrations in Allium cepa induced by PPECS (e-l) and the control (a-d): normal prophase (a), normal metaphase (b), normal anaphase (c), normal telophase (d), stick metaphase (e), disturbed anaphase (f), ana-

Publisher's Note Springer Nature remains neutral with regard to jurisdictional claims in published maps and institutional affiliations.
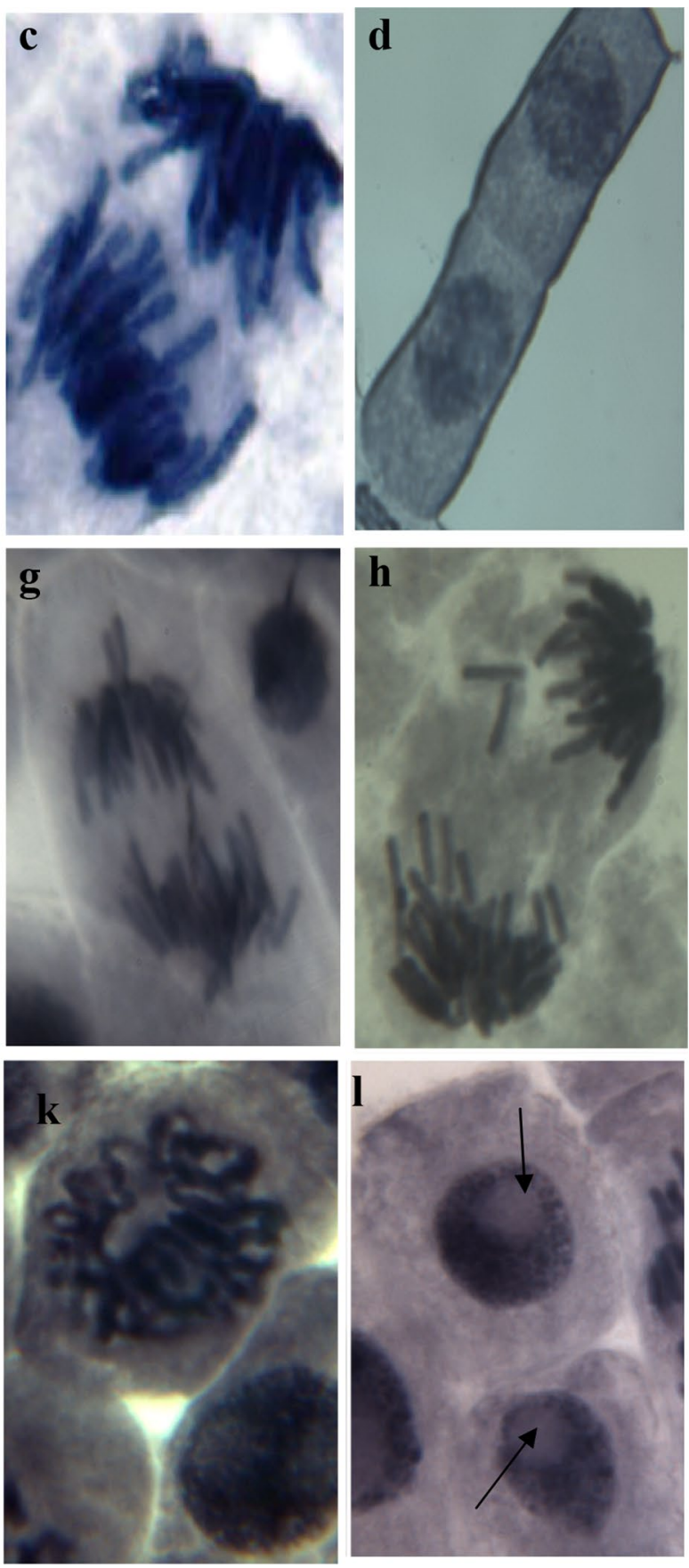

phase bridge (g), chromosome laggards at the anaphase (h), sticky anaphase (i), c-mitosis (j), ring chromosome (k) and 'arrowed' vacuolated nucleus (1) 